\title{
Experiences with Lower-Cost Access to Tactile Graphics in India
}

\author{
M. Bernardine Dias \\ Carnegie Mellon University \\ mbdias@ri.cmu.edu
}

\author{
Mohammed Kaleemur \\ Rahman \\ Microsoft Research India \\ rahman.kaleem@gmail.com
}

\author{
Saurabh Sanghvi \\ Microsoft \\ ssanghvi@microsoft.com
}

\author{
Kentaro Toyama \\ UC Berkeley \\ kentaro_toyama@hotmail.com
}

\begin{abstract}
Tactile graphics allow the visually impaired to perceive twodimensional imagery, which is an essential part of experiencing the world and learning several subjects such as science and geography. In the developed world, such graphics are available to blind students from an early age, and students grow up familiar with tactile representations of images. The production of tactile graphics, however, requires extensive manual labor by sighted people, or costly graphical braille printers. Thus, blind students in developing regions often grow up without any exposure to these learning aids and as a consequence are often prevented from studying the sciences.

In this work, we explore the potential of enhancing access to tactile graphics in the developing world through a software tool that can convert images to a form that can be printed as tactile images using lower-cost braille text printers. We investigate the effectiveness of this tool in producing different types of tactile graphics, and also explore the impact of these graphics on students and visually impaired teachers at a school for the blind in India. We find that our subjects are highly enthusiastic about tactile graphics, are quickly able to understand them, and learn how to write the alphabet using them.
\end{abstract}

\section{Categories and Subject Descriptors}

K.4.2 [Computers and Society]: Social Issues - Assistive technologies for persons with disabilities.

\section{General Terms}

Design, Experimentation, Human Factors.

\section{Keywords}

Assistive technology, braille, tactile graphics, visual impairments, developing regions

\section{INTRODUCTION}

Images are an integral component of many educational texts; especially in science, mathematics, and engineering. In fact, some science text books can have as many as half their pages dedicated to images and graphical representations of the presented topics [19]. Historically, blind students have been denied access to these

Permission to make digital or hard copies of all or part of this work for personal or classroom use is granted without fee provided that copies are not made or distributed for profit or commercial advantage and that copies bear this notice and the full citation on the first page. To copy otherwise, or republish, to post on servers or to redistribute to lists, requires prior specific permission and/or a fee.

$A C M$ DEV'10, December 17-18, 2010, London, United Kingdom. Copyright 2010 ACM 978-1-4503-0473-3-10/12... \$10 important graphical materials because it is cheaper and easier to omit graphics from a textbook being translated to braille, than to include tactile versions of these graphics [19]. However, studies have shown that tactile graphics (representations of the image in a form that makes the content accessible by touch) have great value for visually impaired scholars of science and technology; and that tactile perception is the best modality for comprehension of graphical images by blind readers ([28], [11], [15]).

The importance of access to tactile graphics in the visually impaired community is underscored by the many studies and innovations on this topic. Resources and guidance for creating tactile graphics are easily located both online and in printed form [19] in many parts of the world, and several technology tools have been developed to produce and enhance tactile graphics in developed regions.

Despite the importance of tactile graphics for the visually impaired community, especially in accessing scientific and mathematical information, due to the time consuming laborintensive process of producing these graphics, a large number of images are omitted from science and engineering textbooks. Therefore several research endeavors are dedicated to automating the production of tactile graphics. Way and Barner [23] published a widely cited article that provides useful information about the human sensory system, tactual perception, access technology for tactile graphics production, and relevant image processing techniques. Examples of such automated tools include the TACTile Image Creation System (TACTICS) [24], the TeDUB (Technical Drawings Understanding for the Blind) project [10][17], the Tactile Graphics Assistant (TGA) [22], and the Accessible Graphing Calculator (AGC) [10]. Most of these tools however require the use of a braille embosser that can generate tactile images.

\subsection{Braille Embossers}

Braille embossers are hardware that can convert and print regular text documents in Braille [2]. They are different from ink-based printers in that they use embossing pins to create depressions on paper [5]. Here, braille translation software is first used to convert a text document into a form that can be printed by the embosser. The paper used is generally thicker and heavier than regular paper, and hence costs more. American Thermoform, one of the leading sellers of braille paper sells 1000 sheets of braille paper for about \$40 [3]. Both single and double-sided embossers are currently available. The price of a braille embosser depends on the intended volume of production and can vary between $\$ 1,800$ and $\$ 80,000$ [5].

Image embossers that can generate tactile images are available today in many parts of the world, but at a high cost. These embossers are available with a variety of capabilities and span a 
significant price range. Some popular models include the Index Braille 4X4 Pro embosser [9], the Triple Impressions system [27], and the ViewPlus Emprint SpotDot Color Braille printer [8]. The table below surveys the key features and costs of several braille embossers currently available for purchase.

Table 1. A survey of braille embossers.

\begin{tabular}{|c|c|c|}
\hline Name & Key Features & $\begin{array}{l}\text { Cost } \\
\text { (US\$) }\end{array}$ \\
\hline $\begin{array}{l}\text { Basic-D by } \\
\text { Index Braille }\end{array}$ & $\begin{array}{l}\text { Cannot emboss images; Tractor fed } \\
\text { paper; Z-Folding }\end{array}$ & 3,295 \\
\hline $\begin{array}{l}\text { Everest by } \\
\text { Index Braille }\end{array}$ & $\begin{array}{l}\text { Embosses documents, Braille books, } \\
\text { labels and visiting cards; Can use ink } \\
\text { and Braille in same document }\end{array}$ & 4,495 \\
\hline $\begin{array}{l}4 \times 4 \text { Pro by } \\
\text { Index Braille }\end{array}$ & $\begin{array}{c}\text { Can emboss images with WinBraille; } \\
\text { Newspaper format }\end{array}$ & 5,995 \\
\hline $\begin{array}{l}\text { Emprint } \\
\text { SpotDot by } \\
\text { ViewPlus }\end{array}$ & $\begin{array}{l}\text { Print the original ink text together with } \\
\text { Braille allowing sighted reader to } \\
\text { follow along; embosses images; New } \\
\text { easy-to-use operator panel with tactile } \\
\text { buttons; Uses the same paper and ink } \\
\text { cartridges as an HP Inkjet printer }\end{array}$ & 6,995 \\
\hline $\begin{array}{l}\text { Premier } 80 \\
\text { by ViewPlus }\end{array}$ & $\begin{array}{l}\text { High-speed braille along with Tiger } \\
\text { super-high-resolution graphics ; } \\
\text { Automatic double-sided embossing- } \\
\text { no flipping the paper; Production- } \\
\text { strength hardware made for running } \\
\text { long hours; Compact desktop size-- } \\
\text { smaller than most production } \\
\text { embossers }\end{array}$ & 9,995 \\
\hline $\begin{array}{c}\text { 4Waves Pro } \\
\text { by Index } \\
\text { Braille }\end{array}$ & $\begin{array}{l}\text { Can emboss images with WinBraille; } \\
\text { High embossing speed; } 4 \text { modules }+ \\
\text { one service module; Low noise level }\end{array}$ & 31,500 \\
\hline
\end{tabular}

Despite their many capabilities, these braille embossers are prohibitively expensive for many organizations; especially in developing communities - the lowest cost image-embosser on the market $(\$ 5,995)$ retails for approximately twice the cost of the lowest-cost braille text embosser $(\$ 3,295)$. One option for a lower-cost braille embosser [14] is the Automatic Braille Embosser (BPRT) [2], which is a Perkins Brailler (costing between $\$ 690$ and \$1050) [5][20], modified for computercommanded braille text embossing, and produced by Webel Mediatronics Limited. All of these lower-cost options will be able to create tactile images through our proposed solution.

Most schools in developing regions do not have access to image embossers. In fact, many of these schools do not even have access to traditional text braille printers. Educational materials in braille are often provided to the schools by the national authorities, resource centers, non-profit organizations, or libraries [20]. Most of these resource centers also only have access to braille text embossers. The BrlGraphEditor [15] and the Sparsha Chitra system [1] are two software tools that allow embossing of images on text-only braille embossers.

The BrlGraphEditor is an automated tool designed to transform graphical images, such as diagrams and graphs, into a tactile form. It offers a variety of image-processing features to generate good tactile forms. This tool was not created for developing regions and is catered to be used to for higher education. The Sparsha Chitra system accepts information in HTML format such that additional text can be included along with the tactile representation of the image. It also has basic image editing features such as the capability to view, edit, scale and invert the color of images before they are embossed, but seems to be limited in its ability to handle generic imagery. However, there are no results of usability tests with blind users on the potential of images generated by these tools.

\subsection{Research Contributions}

Our work reported in this paper has four major research contributions. First, we perform a baseline investigation of several schools for the blind in South India, with respect to their use (or lack thereof) of tactile graphics. Despite a stated desire for tactile graphics, none of the schools have been able to introduce these graphics because of high costs. Most of the schools cannot even afford a braille text embosser, and the one school that did have one, could not afford one with native image capability. Second, we describe a redesigned software tool for converting standard images into input for a text-only braille embosser, based on similar existing designs [15][1]; ours has been targeted specifically for use by the sighted staff at a school for the visually impaired. We chose to target sighted staff because we found that most schools and non-profit institutions had sighted staff operating embossers, and all other technology. The solution still requires a braille embosser, but one that is significantly lower in cost than those with image-embossing capabilities. Third, we conduct a series of preliminary field tests with a class of visually impaired students and teachers who exist in large number in developing regions, namely those who have not had access to tactile images previously. Finally we report the results of our field tests which demonstrate both the need and impact of these images on the quality of education and the overall quality of life for visually impaired communities in developing regions.

\section{BACKGROUND}

\subsection{The Mathru School for the Blind}

The Mathru School for the Blind is a residential school that provides free education, clothing, food and health services to visually impaired children from socially and economically deprived families in remote areas of the Karnataka region. The school provides opportunities for the students to develop a variety of skills through activities such as dance, drama, music, computer lessons, and vocational training. The school is located in a residential area, Yelahanka (a suburb in Bangalore, India) and primarily funded by philanthropic donations from individuals and organizations in the local and international community.

The school was established in 2001 and currently, there are 73 students spread across grades one through eight. There is also a group of graduating tenth-grade students who were promoted due to their skills and aptitude. $75 \%$ of the student population is completely blind and the remaining $25 \%$ is partially visually impaired with deteriorating vision. Five of the eight teachers at Mathru are also visually impaired. These five teachers reside at the school and supervise the daily activities of the students, ensuring that daily needs of each student are met adequately. Most of the instructors at the school have earned a diploma in teaching visually-impaired children. The school has also enabled three instructors to attend higher education courses in the past. Although there are courses that are currently offered by the National Association for the Blind (NAB), instructors are unable to participate in them due to a lack of time. 


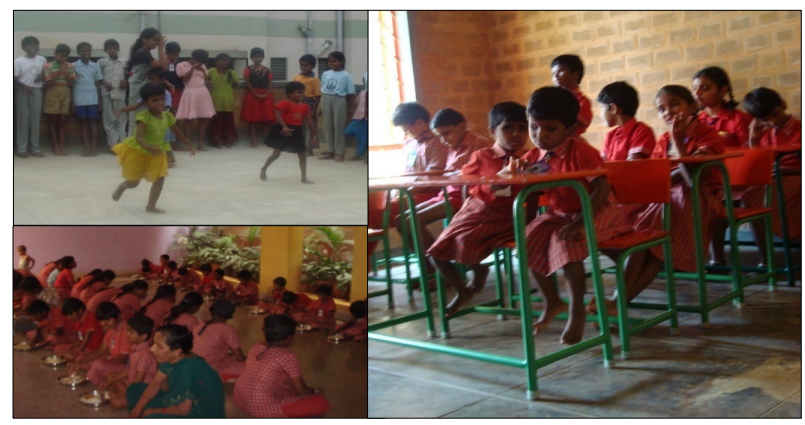

Figure 1. The Mathru School.

Instruction at the Mathru School takes place in both English and Kannada, the native language of the students. It is important to note that many of the students are not fluent in spoken English. Students also learn how to read and write braille, and lessons are primarily taught by dictating facts and procedures. The emphasis on dictation is often a consequence of the lack of access to teaching aids that substitute for more ubiquitously used visual aids and is representative of most blind schools in developing regions.

\subsection{Problem Details and Scope}

According to the 2009 WHO fact sheet, there are 314 million visually-impaired people worldwide and $87 \%$ of them live in developing countries [29]. 45 million people are classified as blind of whom, the majority belongs to India [12]. In India, blind children may attend regular public schools where both visually impaired and non-visually impaired students are integrated or residential schools created specifically for the visually impaired. Although several technology aids are available to visually impaired people in developed countries, due to high cost, these tools are often not accessible to people in developing communities. Most schools for the blind in the United States are well-resourced with PCs, high-quality braille embossers, electronic teaching aids, and so forth; Mathru, while striving to provide access to technology and relevant training (there are a total of $10 \mathrm{PCs}$ in the school and one braille text embosser), nevertheless falls short of typical schools in the United States. Furthermore most schools in developing communities who have advanced technology such as a braille embosser receive the technology through donations.

One specific instance of this difference is that in wealthier schools, there are many teaching aids for visual concepts, allowing blind students to build a strong sense of shapes and tactile perception of images that enables them to experience the world using sensors other than vision. These educational tools range from plastic molds, to embossed maps, and imageembossing printers. They are used to teach subjects such as mathematics, geography, physics and biology, in which sighted people take images, maps, and diagrams for granted. Diagrams, charts, graphs, maps, and other non-verbal displays are encountered increasingly in all educational materials. The ability to understand these graphics is becoming expected of all educated adults [13]. However, at Mathru, images are not part of the curriculum, and at the time when we investigated, neither students nor teachers had ever been exposed to the concept of twodimensional imagery, in tactile form or otherwise. This was largely due to the prohibitive cost of producing or obtaining educational materials with tactile images ([6], [26], [21]).
Our discussions with teachers and students at the Mathru School revealed a significant desire for images in the school's curriculum. The teachers explained their difficulties in teaching subjects like mathematics, science, and geography especially when trying to explain shapes, diagrams, maps, and the human anatomy. When local-language textbooks are translated into braille, pictures are omitted and references to them are deleted. In the first and second grades, images of basic shapes are removed and figures are omitted. In the seventh grade, pictures of internal organs such as the brain, lungs, and heart are omitted. In the tenth grade, students learn history and geography without the aid of maps.

To verify that students were, in fact, unfamiliar with twodimensional imagery, we asked several tenth-grade students to explain how India was shaped. The students were able to recite some facts such as "India is a peninsula that has many rivers" but were unable to explain the shape of India or to appreciate the meaning of a peninsula. They only knew to recite the words of their teachers. The lack of access to images results in students memorizing facts as verbal assertions, without associating them to concrete mental images. We also learned that students at Mathru stop learning mathematics and science after the seventh grade, and they concentrate exclusively on the humanities. This is in part because students find it extremely difficult to understand the image and graph-rich curricula in advanced mathematics and science. Many of the visually impaired teachers at Mathru themselves were deprived of an education in these concepts.

These problems are not isolated to the Mathru School - in fact, Mathru is a relatively well-resourced institution, in a developingcountry context where no more than $10 \%$ of public primary schools have PCs [17]. We visited four other schools for the blind (three secondary schools and one higher-secondary school) in the area and discovered that none of these schools had been exposed to tactile images either. Just like Mathru, these schools steered away from teaching mathematics and science in middle school and focused more on music and political sciences. These factors partially contribute to the prevalent belief in India that visually impaired people are less intellectually capable (in contrast, no such association is made with blind people in developed countries). An added consequence is reduced job opportunities for the visually impaired.

To further verify the value of tactile images at the Mathru School, we carried out a simple experiment. We created an outline image of an elephant consisting of braille dots (shown in Figure 2) using an ordinary slate and stylus. Because the slate is designed only for writing braille text, it limits where dots can be placed and the image is formed from individual braille characters which are used for their spatial configuration, not for their semantic association with the alphabet; in effect, the result is a braille version of "ASCII art." We then presented it to a group of blind students in tenth grade, and the students were asked to identify the picture.

At first, they were confused and unable to understand that it was an image that was placed in their hands. Most tried to "read" the image as braille text, pronouncing the individual letters that formed the image. Even after it was verbally explained to them that it was an image, and not braille text, the students were not able to guess the image content. 


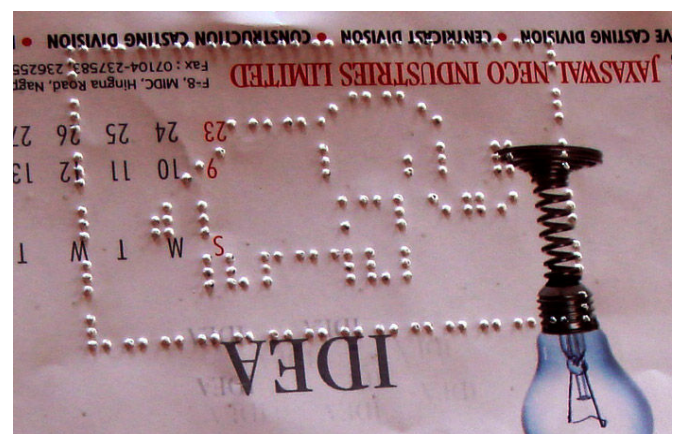

Figure 2. Image of an elephant embossed using a slate and stylus.

Ultimately, one of the boys who was only partially visually impaired was able to identify the image as an elephant by examining the image up close with his eyes. This revelation then propagated among the students who were completely blind. They were still unable to make sense of the image, but understood that it was not to be read as text. When we indicated to them that the long nose of an elephant was represented by the thin, curved structure to the right, and so on for the ears, legs, and tail, they began to understand. It was only by relating the image directly to word-based facts they had learned about elephants that they could relate the tactile image to a "known" object. They were also able to perceive that the legs were thicker than the tail.

Although based only on our anecdotal observations, we believe this was the first instance that these particular students understood that generic objects - and not just words or specific instances of shapes that they might have learned through the finite set of plastic shapes available to them - could be represented on a sheet of paper as three-dimensional images through embossing. Psychologists have noted that the blind have cognitive representations of two-dimensional entities even without being able to see images [14][14].

On the other hand, comprehension of the concept of imagery was not thorough in this short experiment. For example, one of the girls wanted to duplicate the elephant with her own slate. She used a reasonable strategy of copying Braille characters (again, as one might think of copying ASCII art). She, however, ended up with a distortion that sliced the elephant horizontally - she was more concerned about copying the individual letters, than in preserving the overall shape. We followed the elephant example with a tactile image of a camel and again, only the partially visual student was able to identify it as a camel immediately. The other students seemed to recognize it as an animal, but were still slow to perceive the hump as a hump, and so on.

Nevertheless, further motivated by the success of this simple experiment and the excitement of the students, we began to consider how tactile images could be easily produced at Mathru. Further discussions with students and teachers at Mathru and a survey of the relevant literature informed us of the available options and the related challenges.

\section{PRINT-TO-BRAILLE CONVERTER}

The intent of the software tool is to convert images into a document with braille characters that can be printed using regular text-braille embossers, which are lower in cost by at least a factor of two than braille printers that can emboss imagery. Essentially, the tool translates the images to text characters whose corresponding braille patterns, when printed, reproduce the original image in tactile format.

Several constraints must be taken into account when designing this tool. We do not have control over the size or height of the dots and the locations where they can be embossed; these are standardized parameters [25]. The Mathru School used braille sheets that are $11 \times 11$ inches and the embosser can print 28 rows and 42 columns of braille cells (or a periodic, but irregular grid of $84 \times 84$ dots). Each braille dot has a diameter of $1.5 \mathrm{~mm}$ with the distance between adjacent rows fixed at $2.5 \mathrm{~mm}$ and the distance between adjacent columns fixed at $2.4 \mathrm{~mm}$. The distance between adjacent cell columns (measured from the last column of one cell to the first column of the adjacent cell) is approximately $4 \mathrm{~mm}$, and the distance between adjacent cell rows (measured from the last row of one cell to the first row of the adjacent cell) is approximately $5.5 \mathrm{~mm}$. These distances are measured between the centers of two dots in adjacent cells. These dimensions are illustrated in Figure 3. Furthermore, each braille cell can have up to 64 (or $2^{6}$ ) unique dot patterns.

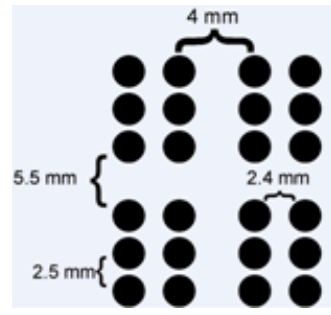

Figure 3. Dimensions for printing Braille characters

The overall vision for this software tool is to allow arbitrary print images to be converted for embossing by the braille printer, and to generate a freely accessible online library of educationally relevant images. The tool is designed for sighted users, since they are still required to identify and locate images on the printed page. Sighted users can select relevant images, convert them into the required format using this tool, and make these converted images available to visually impaired teachers and students. For the first version of this project, we restricted our scope to line drawings and solid (filled-in) shapes.

\subsection{Implementation}

The Braille sheets used at Mathru consist of an $84 \times 84$ dot grid and our high-level approach was to consider each of these dots as a pixel comprising a larger image. To produce tactile graphics, pictures need to be resized and converted to a binary form that indicated which pixels were important and hence needed to be embossed.

When we find a suitable image to be printed, depending on the size of the picture, we resize it so that it can fit within an $84 \times 84$ pixel frame. We use bicubic interpolation to preserve as much detail of the picture as possible and maintain its sharpness. Upon resizing, the image usually loses a considerable amount of detail. Hence, we threshold and binarize the image to bring out the dominant lines. Our thresholding technique is iterative, and designed to converge to a good threshold. We start with an initial brightness threshold factor, $T_{i}$, of 0.5 and then traverse through each pixel. If the brightness of a pixel is greater than the initial threshold, we add it to a set $S_{1}$. Otherwise, we add it to a set $S_{2}$. The averages $a_{1}$ and $a_{2}$ of the values in the sets $S_{1}$ and $S_{2}$ are computed respectively. The average of $a_{1}$ and $a_{2}$ then gives a new threshold $T_{f}$. If $T_{f}$ equals $T_{i}$, we choose it as our threshold. 
Otherwise, we take $T_{f}$ as our new $T_{i}$ and keep repeating the thresholding process until an equilibrium state is reached.

Next, we generate a binary image from the original image in which pixels that are above the threshold are marked (i.e. colored black), and ones that are below the threshold are colored white. The pixels that are marked will be embossed in the final image.

American Grade 2 braille standard font [7] is the most commonly used font in translation software. However, we used the American Grade 0 braille standard [4] (the basic from of American braille) to determine characters for each of the cells and print the sequence to a text file. In this font, contractions (shorthand for words) are not used, and instead, a single braille character is used to represent each English character. Furthermore, each character in a text file is translated individually without consideration for the characters surrounding it which is critical for maintaining the spatial configuration of the braille dots that form the tactile image. These factors made the chosen American Grade 0 braille standard more suitable for our approach.

We maintain a table $H$ of all 64 character mappings in the American Grade 0 braille standard. Each $3 \times 2$ block of pixels in the image is considered to be a braille cell, effectively rendering the binary image as a $28 \times 42$ braille cell grid. Each of these blocks contains varying combinations of marked and unmarked pixels. Each block in the image is then traversed from top to bottom, left to right. While traversing the cells, the marked pixels in each cell are compared with the patterns in $H$ to determine a Grade 0 character representation. Since $H$ consists all possible $3 \times 2$ patterns, everything will map to something in $\mathrm{H}$. Each of these characters is written to a text file. On completion of this process we obtain a text file containing character representations for each braille cell block of the binary image. This text file can then be opened in WinBraille using the Grade 0 standard, and embossed to generate the desired picture in tactile format. The entire tactile image generation process is graphically demonstrated in Figure 4 - Figure 8.

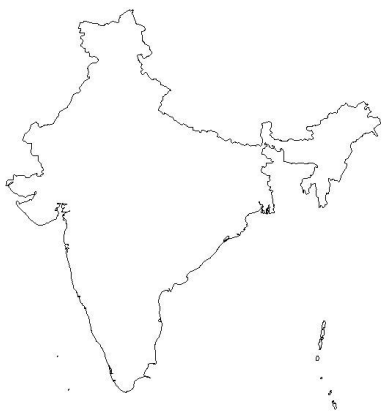

Figure 4. Original image showing a map of India.

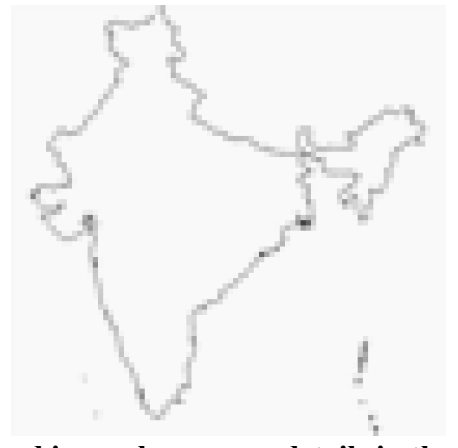

Figure 5. Resized image loses some details in the re-sizing process.

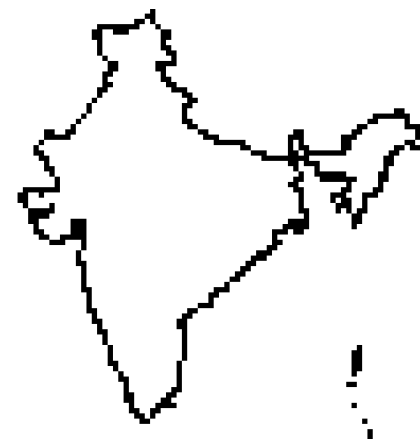

Figure 6. Thresholding the resized image produces a binary image.

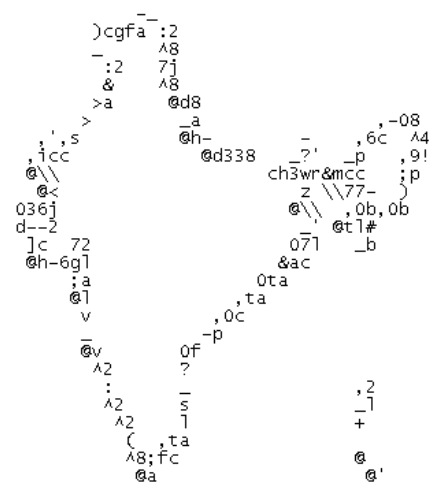

Figure 7. A text file is generated by mapping each cell block of the image to a corresponding braille character.

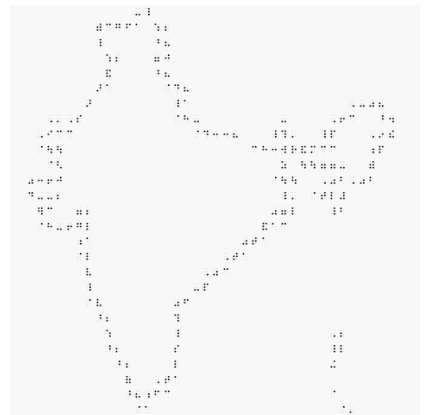

Figure 8. The final embossed tactile image.

\section{PRELIMINARY FIELD TESTS}

Having implemented our solution, we conducted a set of preliminary field tests at the Mathru School to evaluate the tactile images we produced. By bringing tactile imagery to Mathru's students, we were able to observe a novel circumstance that to our knowledge has not been closely examined before, and which will likely be far more common in developing countries than in developed countries. Namely, a group of teachers and students who have some basic education, including knowledge of braille, but not exposure to tactile imagery, are being introduced to tactile imagery for the first time.

It is in this context that we hoped to better understand the answers to some of the following questions:

- Can blind people make sense of tactile images, even if they have not grown up with them?

- What challenges do those newly exposed to tactile images face? 
- What kinds of images are most desired by teachers, students, and standard curricula?

- What kinds of features could further support learning with tactile images?

- Can tactile images be used to teach blind people how to write letters in print?

- What are the limitations of tactile images?

Our study involved four phases of open-ended interviews and exploratory teaching activities with various combinations of teachers and students at Mathru and the National Association for the Blind Karnataka branch (NAB). The students we tested at Mathru were between the ages of 4 to 19. The group we tested had an equal ratio of boys and girls and most came from impoverished communities. At NAB, we tested 8 students ( 6 boys and 2 girls). All of these students were above 18 and had a variety of educational backgrounds. In our test group 6 of students had completed secondary schools while the other 2 had dropped out from secondary school. One student in the group only lost his eyesight after completing $8^{\text {th }}$ standard.

These preliminary studies took place over five weeks at the Mathru School and one week at the National Association for the Blind. Each session informed the design of the next.

Since the study was generative and informal in nature, we set a short-term goal for ourselves that would anchor the investigation and provide some direction: to create a library of tactile images that would be immediately accessible and pedagogically effective for the teachers and students of the Mathru School.

\subsection{Initial Feedback}

We wanted to start with a smattering of different types of tactile images, to get first impressions from the teachers and students. So, we worked with the visually impaired teachers, exposing them to a test set of tactile images and asked them to select images that were easy to identify, images that would be beneficial for students, and images that are feasible for teachers to incorporate into the curriculum. They chose illustrations of an apple, human figure, cat, the letter ' $\mathrm{M}$ ', and a map of India - these were all concepts that were very familiar to everyone, and also spanned a diverse range of subjects. For each of the five objects we had both an outline illustration (where dots created the outline of the image) and a filled-in illustration (where the entire object shape was filled with dots).

We then selected two blind teachers, who were not part of selection process of test images, and ten blind students from $7^{\text {th }}$ grade and above, and asked them to identify ten different tactile images. These preliminary test images were very well received, and students and teachers were able to identify most of the images. 8 out of 10 students and both teachers were able to identify the apple, human figure, and cat. In addition, this same group was able to identify that the map of India was some kind of map but only one teacher and three students identified the map as India. Only one teacher who had prior knowledge of print was able to identify the letter 'M.'

The students who found it challenging to identify the images either had difficulty in tracing the outline or grasping the concept that the dots formed an image instead of representing braille text. Once the students were told what the picture was they were able to retrace it and explain the different features of the picture. For example, when we presented an image of a human figure, all ten students were able to identify the principal anatomical features.
We observed that students and teachers preferred outlines for maps because this gave them a better understanding of space. They explained that since the images were not filled with dots, it was easier for them to identify different regions within the image. However, for images like basic shapes, letters and solid figures like that of animals, they preferred filled-in pictures as it was easier to identify the overall image. 9 out of 10 students were able to grasp the overall shape of the letter ' $M$ ' effectively. One of the students continued to try to read the individual cells of the image instead of feeling for the shape.

\subsection{Teaching Simple Shapes Using Tactile Images}

Our next test was to explore avenues for incorporating simple shapes into the curriculum at Mathru. We worked closely with one of the visually impaired teachers to test the hypothesis that first- and second-grade students could comprehend tactile images of basic shapes. First, we created a set of basic shapes and asked the teacher to identify them. She was able to identify all of the shapes without any assistance. The basic shapes included a triangle, square, pentagon, hexagon, heptagon, circle, semi-circle, trapezoid, rectangle, and a cricket bat and ball.

The teacher then worked individually with fifteen first- and second-grade students. First, she got each student to understand the concept of moving their fingers along the outline. Next, she asked the student to identify the key elements of the pictures. For example, she asked students to point to the five sides of the Pentagon.

After going through several pictures, 9 out of 15 students were comfortable tracing the outline of shapes without help from the teacher. The others struggled with differentiating the characteristics of the shapes and rushed to identify what an image was before tracing the entire outline. The immediate success of the experiment showed that tactile images of basic shapes are easy to interpret and can be incorporated into the curriculum as early as first grade.

\subsection{Using Legends in Tactile Images}

Discussions with the teachers and students at Mathru revealed that there was a major problem teaching internal organs, maps, and other complex diagrams with many details. Creating details within outlines in the tactile images made it extremely difficult for students to determine whether the detail was part of the outer outline or a detail inside the image. We investigated several approaches to find a method that would clearly denote details within images. These approaches included having text descriptions within images, splitting images into several parts, and using a legend . In wealthier communities captions are used to tell students how to interpret the image.

We finally settled on a method that used symbols for different parts of the image and included a legend on the side explaining what each symbol represented. This method was chosen because inner features were differentiated from the outline and the perception of space was better represented. The legend approach made a clear distinction between what was part of the image and what was text; this distinction was unclear in the other approaches. For example, on a map of Karnataka, single letters were used to denote major cities. A legend was then used to list cities corresponding to these letters as shown in Figure 9. 


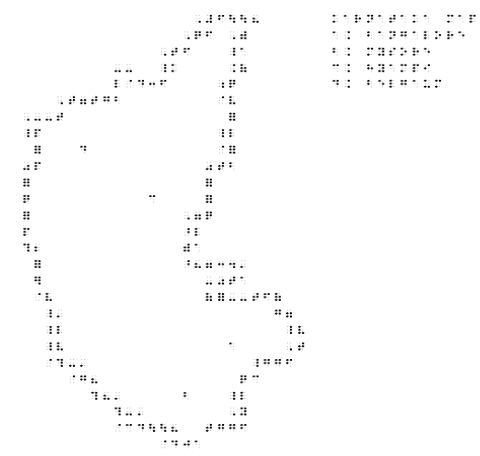

Figure 9. Map of Karnataka with major cities marked. A legend at the top right corner maps symbols to cities.

A group of five students from $10^{\text {th }}$ grade and a teacher from Mathru, and another group of eight students (who had completed $10^{\text {th }}$ grade) from the Karnataka branch of the NAB were tested to see whether they could understand the details within images. We selected test images that included a map of India with the Karnataka region filled with dots, a map of Karnataka with major cities, and diagrams of the human brain, heart, and lungs.

First, the students were instructed to read the legend and get an overview of the image. We then taught them how to use the legend by locating the symbols from the legend in the image. The students were able to identify the different cities and regions in the maps, and parts of the internal organs. After learning the concept of legends, 8 out of the 14 participants were able to effectively use the pictures without our help.

The other 6 participants had a hard time understanding the concept of the legend. They failed to grasp the fact that the legend mapped symbols to features in the image. None of the 14 students had been previously exposed to anything with a legend. These images also enhance the learning experience for students especially in map-intensive subjects like history and geography. Furthermore, many teachers did not have accurate views of the internal organs and the tactile images helped them to dispel many misconceptions. For example, teachers did not know about the bronchioles inside of lungs and they believed there was nothing inside of the lobes of lungs.

One specific example involves the tactile image of the map of Karnataka. Previously, students knew the names of several different cities in Karnataka but did not know anything about their locations relative to Karnataka. Using the tactile image of the map, teachers were able to explain directions and ask students to determine the proximity of cities. Students answered questions such as "If you are in Bangalore is Mysore closer or is Mangalore closer?" And "What part of Karnataka is wider - the North or the South?" For the first time, students were able to understand the concepts of relative spacing, direction, and size.

\subsection{Using Tactile Images to Teach Handwriting}

With these encouraging results, we considered a challenge heretofore not considered at Mathru: teaching handwriting to blind people who had never used a pen or pencil to write. In fact, many of the blind teachers who had taken part in the various exercises, expressed a keen interest in learning to write their name (not in braille, but with written letters) so that they could sign legal documents and thereby more easily gain access to services such as banking. For this experiment, we created tactile images for the entire uppercase English alphabet in print. A sample picture of one of these tactile image sheets is shown in Figure 10.

We conducted 6 hour-long instructional sessions over the course of 2 weeks to teach these images to 10 students and 2 teachers at Mathru. All the students that we tested were in grades 6 and above. We decided to work with this age-group because students in lower grades were still mastering how to write in braille and we did not want to have students confuse braille and print. Each of these hour-long sessions focused on explaining how these images should be used. Students who did not have prior experience holding a pen were given training sessions to teach them how to grip a pen, and how to draw straight lines and curves.
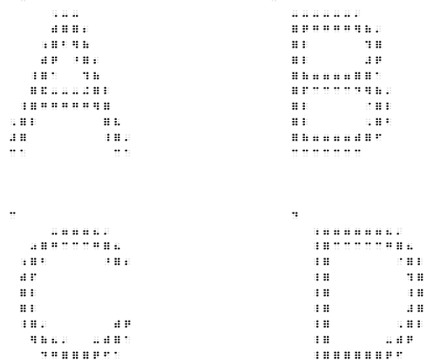

Figure 10. Embossed letters A, B, C and D. As a key, the braille representation of each letter appears to the upper-left of each character

Once a student was able to grip a pen, we conducted writing sessions. During the first 30 minutes we helped students learn the shapes of the letters. We noticed that students could use their second hand (the one they weren't using to write) to keep track of what was written. This technique worked well to write letters that had a horizontal line at the center such as 'A' and 'H.' Students were also taught how to feel the entire outline of each letter. During the second half of the session we allowed the students to teach each other or work alone, and we observed their progress. At the conclusion of these sessions 3 students and 1 teacher were able to write the entire alphabet as well as sentences in print. A sample of one student's print writing is shown below in Figure 11. All participants in the study were able to successfully write some letters, but some had difficulty controlling the pen and remembering the different shapes corresponding to the letters.

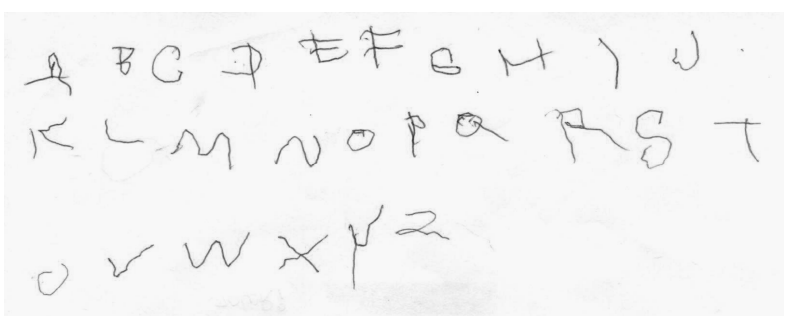

Figure 11. A sample of a student's writing.

The instructional sessions for handwriting demonstrated that it is possible to teach handwriting to teachers and students; especially in $6^{\text {th }}$ grade and higher. Since all participants in the study showed clear improvement during the instruction sessions, we can reasonably conclude that if handwriting classes (using the tactile images) are incorporated into the curriculum at Mathru, all students can learn to write in print. Overall, the tactile images were effective in teaching the basic shapes of the letters to the students and with practice they learned how to recreate these shapes. 
The ability to write enables the visually impaired to sign legal documents, write on checks and envelopes, and communicate through written text with sighted people who cannot read braille. More significantly, the skill of handwriting will also help the visually impaired to be more socially integrated in India. Currently, the visually impaired can only go to banks which allowed people to use thumb impressions to sign checks and official documents. Many of the teachers at Mathru expressed that they find this embarrassing because they do not like being treated differently. One teacher who particularly felt this way studied by herself in the evenings and learned how to write in print within a week! Upon completion of learning how to write, she felt overjoyed and personally wanted to impart this knowledge to every student at Mathru.

While there may be other methods to teach print to the visually impaired, this experiment motivated teachers and students to become comfortable with tactile images and gave them confidence that they could learn to write in print. The results also showed clearly that the visually impaired students could quickly learn how to identify the outlines of each letter and interpret the tactile graphics.

\section{DISCUSSION}

Although the results are preliminary, they clearly demonstrate the educational value of using tactile images.

\subsection{Overall Observations}

An important observation was that people who were exposed to these braille images for the first time perceived them as braille text rather than an embossed image. Instead of feeling the image and getting an overview, they would try to read the image line by line. Another common observation was that teachers became comfortable using the tactile images without a lot of external help. Once they used the tactile graphics it was easy for them to explain to other teachers and students how to interpret the pictures as well. These results highlight the fact that these images can be incorporated easily into the curriculum at different schools. These tactile graphics enabled them to understand concepts that they couldn't fully understand before.

By incorporating images solely made out of braille dots we introduced an idea to students that they could also make art manually using a slate and stylus. Students could now share visual ideas with each other in the form of images. Before our field test at Mathru, braille was only a form of reading and writing; now, students can also draw in braille.

An important observation is the tremendous emotional reaction when a blind person is first exposed to tactile graphics and "gets" it. Previously, graphical knowledge was imparted to them only through oral or written communication, which is simply insufficient for graphical knowledge. These images literally introduced to them a whole new world.

Lastly, when creating tactile images for Mathru we noticed that in order for these images to be effective they needed to be cultural specific. In addition to bringing the technology of being able to produce tactile images, our software provided a way of creating cultural specific images such as a Map of India, or Karnataka. Furthermore our tool differed from current solutions by focusing on making sure visually impaired instructors could easily use the tactile images to teach the students.

\subsection{Design Tips for Braille Image Printing}

When creating images using our tool the following tips are useful. All complex pictures should be captioned so students know what they are looking at. This is analogous to captions provided for images available to sighted people.

Images that have a lot of complicated inner details are not represented well using this tool because students have a harder time identifying the details inside. Instead, a user can design an image with symbols representing the different parts within an outline. Or the user can create multiple images of the same object at different levels of detail. For example, a map of the world should just include the seven continents. This can be complemented with more detailed images of each continent.

The tool works best on pictures with high contrast and simple color scheme. Each braille dot is either on or off so it is difficult to depict different colors. Future work needs to be done to figure out a better way to represent images with multiple colors. One of the approaches could be to vary the concentration of the dots according to a color scheme.

The embossed images can be easily reproduced and distributed at a very low cost. The cost of a single Braille sheet is approximately Indian Rs. 1.5 (US \$0.04). Therefore, printing 100 sheets would cost Indian Rs. 150 (US \$4). Because these tactile images can be easily reproduced, if schools have access to a digital library of these tactile images, they can easily produce and use them in their classrooms as needed. Therefore, throughout our field-work at Mathru, we collected all of the tactile images that were beneficial, and made them available to the teachers through a digital library packaged together with the braille image printing application.

A limitation to be addressed is the lack of image editing capabilities in the tool. The tool faces limitations with regards to the scaling and representation of very large detailed images. When a large image of the world map is scaled down, it loses a lot of detail and this makes it hard to represent on an $84 \times 84$ Braille cell grid. Currently, the user has to perform a list of manual steps in order to convert an image to its tactile form. Future versions should allow users to alter images by adjusting features, such as the contrast, and previewing them before converting to braille.

\section{CONCLUSIONS AND FUTURE WORK}

Image embossing allows the visually impaired to perceive two-dimensional imagery, which is an essential part of learning important subjects such as science, mathematics, and geography. Although these tactile images are relatively prevalent in the developed world, they are often absent in developing regions due to prohibitive production costs. To address this need, we designed solution for converting regular images into a form that can be printed as tactile imagery on low-end embossing devices meant only for printing braille text. This tool was then used to generate tactile graphics for a series of preliminary field tests with blind subjects who had never before been exposed to tactile graphics. We found that teachers and students at a school for the blind in India responded with great enthusiasm. They were quickly able to understand these tactile images, and studying tactile imagery of the alphabet enabled them to learn hand-writing for the first time.

In future work, we hope to make the tool even more accessible to developing-region institutions catering to the visually impaired. We plan to make our software available online, and extend the library of tactile images by allowing users to access the library online and contribute new images to the library. Another area of 
future work is improving the distribution of tactile graphics in developing regions. The Mathru School has volunteered to distribute the tactile images in their possession to other local blind schools at no charge. While this will allow schools in the area to gain access to these images, it is not a comprehensive solution. We hope to offer access to our software application and online library to larger distribution organizations (such as the National Association for the Blind in India) in several developing regions so that tactile graphics are accessible to many more who would need them.

\section{REFERENCES}

[1] A. Lahiri, S. J. Chattopadhyay, A. Basu, "Sparsha: A Comprehensive Indian Language Toolset for the Blind," in Proc. 7th international ACM SIGACCESS conference on Computers and accessibility, October, 2005.

[2] Adaptive Technology Resource Center - Braille Embosser. http://atrc.utoronto.ca/index.php?option=com_content\&task $=$ view\&id $=34 \&$ Itemid $=9$

[3] American Thermoform http://www.americanthermoform.com/brailon.htm

[4] Braille Font. http://www.tsb.k12tn.net/TSB/Vision/Brailleinfo/Braille_fon t.htm

[5] Braille Technology - American Foundation for the Blind. http://www.afb.org/Section.asp?SectionID=4\&TopicID=31\& DocumentID $=1282$

[6] Brailler. http://www.brailler.com/repo.htm

[7] Computer Braille: UEBC's Fatal Flaw? http://www.dotlessbraille.org/fatalflaw.htm

[8] Emprint. http://www.viewplus.com/products/brailleembossers/ink-braille-printers/emprint/

[9] Index Braille. http://www.indexbraille.com/Products/Embossers/4X4PRO.aspx

[10] J. A. Gardner, "Access by Blind Students and Professionals to Mainstream Math and Science," in Proc. 8th International Conference on Computers Helping People with Special Needs, July, 2002, pp.502-507.

[11] J. Gardner, "Access by blind students and professionals to mainstream math and science," in Proc. Computers Helping People with Special Needs 8th International Conference, ICCHP 2002, Lecture Notes in Computer Science Vol. 2398, 2002, pp. 502-7.

[12] K. Sinha, "India has largest blind population," The Times of India, October 11, 2007. http://timesofindia.indiatimes.com/articleshow/2447603.cms

[13] Linda Sheppard and Frances K. Aldrich "Tactile Graphics in school education: perspective from teachers" in British Journal of Visual Impairment, 2001, pp. 93-8.

[14] Lopes, D.M.M., Art Media and the Sense Modalities: Tactile Pictures, The Philosophical Quarterly. 47(189):425-440, 2003.

[15] M. Batusic and F. Urban, "Preparing tactile graphics for traditional Braille printers with BrlGraphEditor," in Proc.
Computers Helping People with Special Needs 8th International Conference, ICCHP 2002, Lecture Notes in Computer Science Vol. 2398, 2002, pp. 535-6.

[16] M. Batusic and F. Urban, "Preparing tactile graphics for traditional Braille printers with BrlGraphEditor," in Proc. Computers Helping People with Special Needs 8th International Conference, ICCHP 2002, Lecture Notes in Computer Science Vol. 2398, 2002, pp. 535-6.

[17] M. Horstmann , M. Lorenz, A. Watkowski, G. Ioannidis, O. Herzog, A. King, D. G. Evans, C. Hagen, C. Schlieder, A.M. Burn, N. King, H. Petrie, S. Dijkstra, D. Crombie, "Automated interpretation and accessible presentation of technical diagrams for blind people," The New Review of Hypermedia and Multimedia, v.10 n.2, p.141-163, December 2004.

[18] M. Y. Ivory, A. P. Martin, R. Megraw, and B. Slabosky, "Augmented cognition: an approach to increasing universal benefit from information technology," in Proc. 1st International Conference on Augmented Cognition, Las Vegas, July, 2005.

[19] P. K. Edman, Tactile Graphics, New York: American Foundation for the Blind, 1992.

[20] Perkins Braillers, produced and distributed by the Perkins school for the blind through Howe Press http://support.perkins.org/site/PageServer?pagename=store homepage

[21] Pro Embosser. http://www.viewplus.com/products/Brailleembossers/Braille-printers/pro-embosser-gen2/

[22] R. E. Ladner, M. Y. Ivory, R. Rao, S. Burgstahler, D. Comden, S. Hahn, M. Renzelmann, S. Krisnandi, M. Ramasamy, B. Slabosky, A. Martin, A. Lacenski, S. Olsen, and D. Groce, "Automating tactile graphics translation," in Proc. 7th international ACM SIGACCESS conference on Computers and accessibility, Baltimore, October, 2005.

[23] T. P. Way and K. E. Barner, "Automatic visual to tactile translation-part 1: Human factors, access methods and image manipulation," IEEE Transactions on Rehabilitation Engineering, vol. 5, pp. 81-94, Mar. 1997.

[24] T. P. Way and K. E. Barner, "Automatic visual to tactile translation, Part II: Evaluation of the tactile image creation system," IEEE Transactions on Rehabilitation Engineering, vol. 5, Mar. 1997.

[25] Tiresias. http://www.tiresias.org/research/reports/Braille_cell.htm

[26] Touch Graphics. http://www.touchgraphics.com/catalog/index.php?cPath=1

[27] Triple Impressions. http://www.brailler.com/timpress.htm

[28] W. Schiff and E. Foulke. Tactual Perception. Cambridge University Press, Cambridge, Eng., 1982.

[29] World Health Organization, "Fact Sheet No. 282: Visual impairment and blindness," May 2009. http://www.who.int/mediacentre/factsheets/fs282/en/ 